\title{
Designing Self-Reflective Visualizations in Patient-Cantered Systems
}

\author{
Archanaa Visvalingam ${ }^{1}$, Jaspaljeet Singh Dhillon ${ }^{2}$, Saraswathy Shamini Gunasekaran ${ }^{3}$, Alan Cheah Kah Hoe ${ }^{4}$ \\ ${ }^{1234}$ College of Computer Science and Information Technology, Universiti Tenaga Nasional, Malaysia. \\ *Corresponding author E-mail: achavisva0196@gmail.com
}

\begin{abstract}
Self-care applications are mostly featured with visuals that educate users to comprehend their health status in taking a proactive role in their healthcare. It is crucial to ensure that these visuals are adequate and meets the expectations of the users. In this study, healthcare visualisation design factors were reviewed from existing studies in identifying their relevance to self-care visuals. The study also conducted a focus group study (FGD) with a group of mobile application users to understand their perception and expectations towards healthcare visuals presented in self-care applications. Results indicate that existing guidelines for healthcare visuals are focused on a specific type of application and they mostly emphasise the usability aspects of the visual and neglect its functionality. The identified themes from the FGD are motivation \& commitment, customizability, personalisation, accessibility, complex yet comprehensible graphs, alerts \& proactive support, and trust \& privacy. Users are expecting healthcare visuals that are self-reflecting, comprehensive and userfriendly in enabling them to better understand their health conditions. A combination of design factors is necessary to aid the development of self-care visuals in health support applications. Hence, the study proposed a conceptual model that lists a set of design principles for self-reflective visualisations in novel health support applications.
\end{abstract}

Keywords: Patient-centered systems, self-care, visualization, self-reflective, design factors.

\section{Introduction}

New design approaches have been introduced by the advancement in information technology (IT) that has been supporting in healthcare delivering and patient education. This progress has empowered a fundamental redesign of healthcare processes based on the use and incorporation of electronic communication at various level. Patients are endowed by the potential of healthcare IT, and it supports them in transitioning from a role in which the patients are the passive receivers of care services to an active role in which the patients are informed, have choices, and are involved in the decision-making process.

Patient-centred systems are defined as tools that enable a partnership among practitioners, patients, and their families (when appropriate) to ensure that procedures and decisions respect patient's needs and preferences. For the patients to have control over their health, it is vital for them to be engaged in patient-centred systems, as their primary goal is to serve patients with patient-centred care. These applications and systems cater for users with different health needs. Most of these applications are self-care tools developed to be used independently by the patients themselves. Commonly, these applications are equipped with visuals or graphical representations that enable users to comprehend their health progress.

Existing healthcare visualization of patient-centered systems can be categorized into (1) web-based health support applications, which enable patients to manage their conditions through online healthcare systems; (2) mobile health support applications that help patients to track their health progress conveniently with their smartphones; (3) stand-alone health monitoring devices, which help patients to monitor a specific health condition; and (4) wearable health monitoring devices that help users to monitor and record real-time vital signs by wearing a device with sensors as an accessory. Figure 1 and Figure 2 show examples of healthcare visuals presented in existing applications.

Data obtained via the applications above are ideally presented visually to have a higher impact on action rather than having words that may be difficult to interpret [3]. Hence, it is common to find trends of health data presented via visuals or graphical representations that help to educate users on their health progress. There are a few types of graphs that are commonly used to represent health data, e.g. bar graphs, pie charts, histograms and line graphs. Health data are presented in the form of graphs to enable healthcare consumers to better understand their health trends with less confusion and complication. These graphs are the evidence of Human-Computer Interaction (HCI) that focuses on the human, social, organisational and technical features of communication between human and machines. Therefore, HCI can be considered to have sizeable cognitive factor where processing of information by humans is closely related with computer systems. Adding to that, HCI in healthcare increases the usability of a healthcare product or application. This is to achieve specified goals with effectiveness, efficiency and satisfaction when healthcare consumers use the product or application. In return, such information would educate them on their health as well as motivate them in being proactive towards their healthcare (e.g. follow the diet and fitness plans) [1]. 


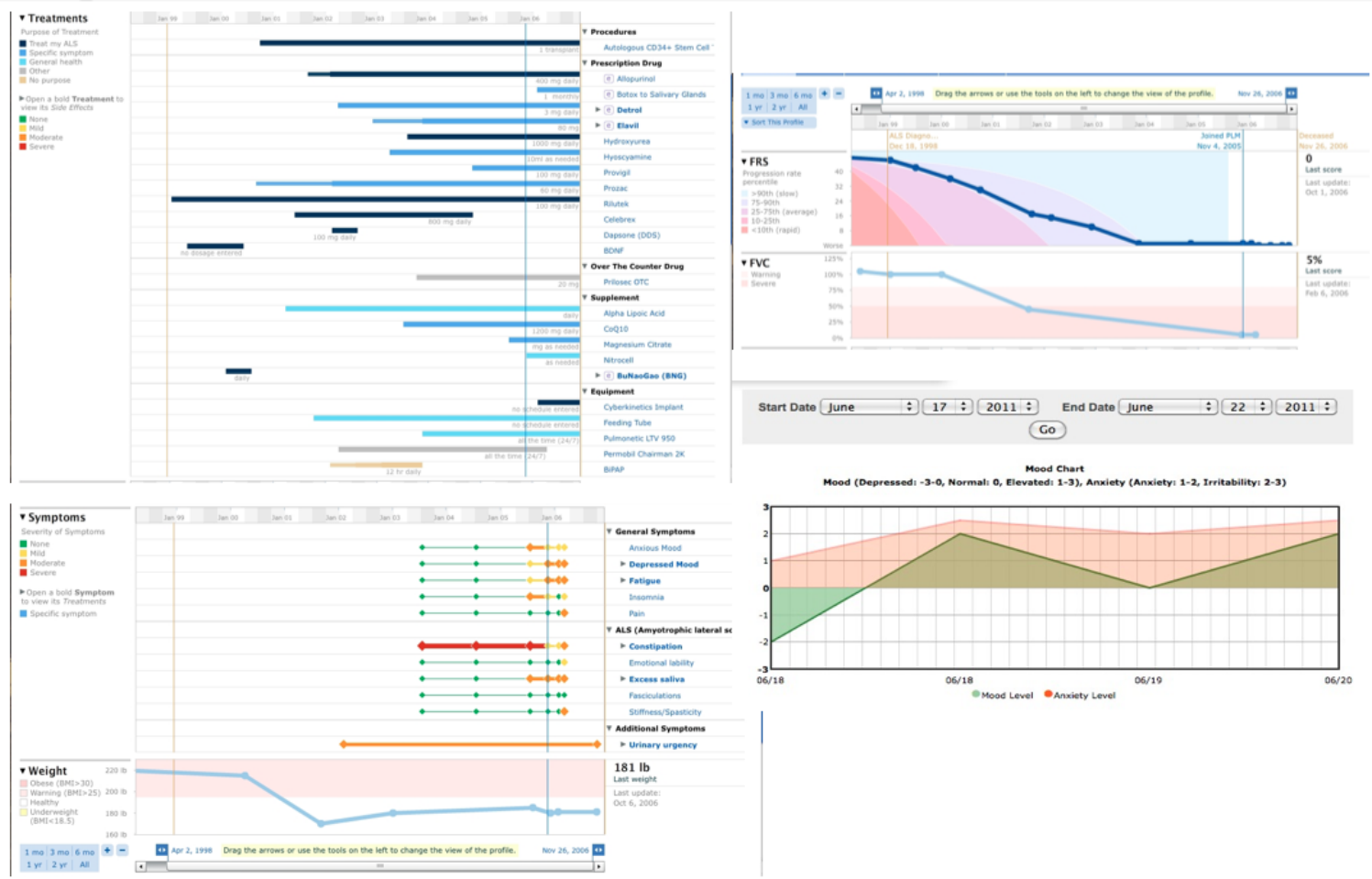

Fig.1: Examples of visuals presented in web-based health monitoring applications.

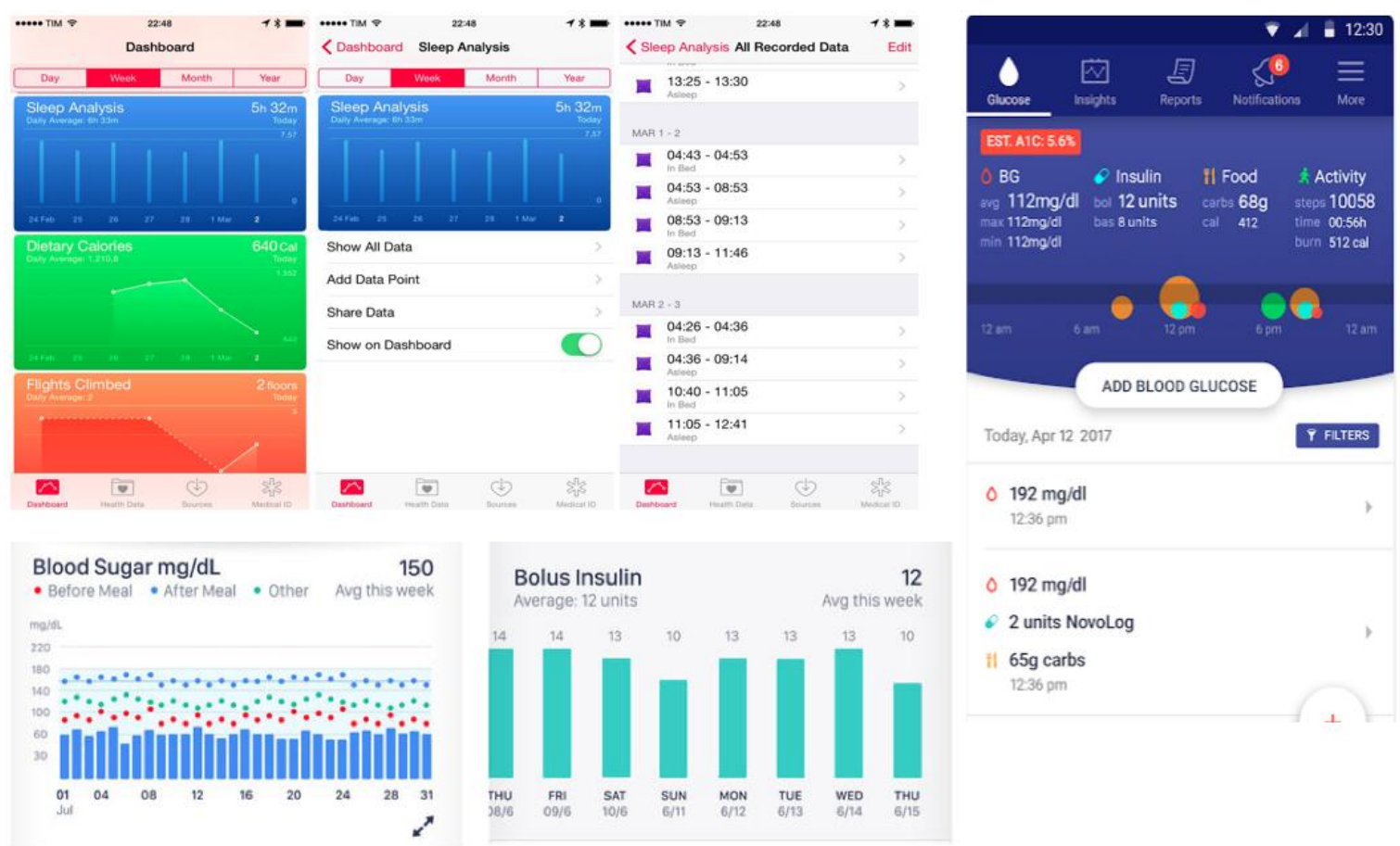

Fig.2: Examples of visuals presented in mobile-based health monitoring applications.

Self-care applications are becoming popular among healthcare consumers. An exceptional example is PatientsLikeMe has more than 600,000 registered members that sharing their health data to track their progress, and learning from the experiences of other patients who went through similar health conditions [16]. Healthcare consumers mostly get attracted to these applications for the value they bring to them as well as the way they are designed and presented. The designs of the visual would create a more significant impact in empowering the users in being more proactive in managing their health. Ideally, self-care applications should present visuals that are self-reflective and comprehensible in ensuring that the visuals are self-explanatory and easily understandable.
In order to better understand one's own health data, the user must have health literacy, which is crucial in comprehending any information presented by health professionals and healthcare providers. The lack of health literacy can result in limitations with patients in interpreting health information and keep track of any medical instructions given and to communicate with their doctors [8]. For example, a person who often falls sick and visits the hospital is more likely to know more about his medical history correctly. He would be knowledgeable enough to possibly treat himself the next time he falls sick. This shows that the more often a person uses the medical services that are available to them the higher their health literacy. Despite having such an advancement in technology, many people do not realise the risks in 
misinterpretation of graphical displays of risk and associated terminology [6]. The problems in misinterpreting a set of data can lead to major confusion within a patient himself, between the patient and his family members or both the parties with the physicians. Moreover, a certain type of graph can also cause confusion and a longer time is taken to understand it. Graphs like circular and area-based graphs are difficult to understand quickly and accurately [7]. The reasons being the area-based charts are not as efficient in the means of comparing quantities and visualising as treemaps and pie charts.

The aim of this paper is to develop a conceptual model listing a set of design principles for self-reflective visualisations in health support applications. The objectives of this paper are twofold: (1) to review and analyse the existing visualisation design factors and (2) to obtain a clear understanding of the requirements and expectations of users towards self-reflective visualisations. We try to answer the following research questions: 1) "what are the types of healthcare visualisation design factors that are currently available?" and 2) "what are the users' perspectives towards healthcare visualisations provided in self-care applications?".

This paper is organised as follows: Section 2 presents the methodology employed in conducting the research. Section 3 reports the results and discussion. In Section 4, a conceptual model depicting the design principles for visualisations in self-care applications is presented. Section 5 wraps up the findings and proposes future areas of the study.

\section{Methodology}

In this section, we present the two different approaches that were employed in the process of identifying the relevant design factors to develop self-reflective visualisations principles for health support applications

\subsection{Literature Survey on Existing Visualisation Design Factors}

For this research, we analysed and reviewed existing visualisation design factors that were aimed to design visuals for healthcare applications. Several papers were selected and retrieved from various databases using a combination of terms as follows: [health application design principles OR design principles OR healthcare application visualisation principles OR visualisation principles OR visualisation scale OR health design scale]. Eleven papers were selected after thorough reading through the abstracts, further analysis and elimination process.

\subsection{Probing User Perception on Self-Care Visuals}

In this section, we report a Focus Group Study (FGD) to discover the users' insights and perceptions towards visuals presented in self-care applications. Eight participants were involved in the FGD conducted in June 2018. The selected participants are of various age groups, gender and ethnicities, who mostly had the experience of using mobile health applications. The focus group session lasted for about 90 minutes. As a preface, the participants were briefed on the objectives, aim and some information about this study. Open-ended questions were used to prompt the discussion. The participants were encouraged to give their comments and opinions throughout the discussion.

During the discussion, printouts of visuals from existing applications from four different categories: (1) web-based, (2) mobilebased, (3) stand-alone devices, and (4) wearable devices were given to the participants in providing a clear picture of the types of visuals that are available in the market today. The discussion was audio-recorded and transcribed later. Characteristics of the participants are displayed in Table 1. Several themes were developed from the discussion. Content analysis method was employed in analysing the data gathered [14].
Table 1: Characteristics of the participants.

\begin{tabular}{|l|c|}
\hline Category & No. \\
\hline Age (Years): & 1 \\
\hline $21-30$ & 4 \\
\hline $31-40$ & 2 \\
\hline $41-50$ & 1 \\
\hline $51-60$ & \\
\hline Group: & 1 \\
\hline Student & 4 \\
\hline IT Lecturer & 2 \\
\hline Researcher & 1 \\
\hline Housewife & \\
\hline Ethnicity: & 3 \\
\hline Malay & 4 \\
\hline Indian & 1 \\
\hline Others & \\
\hline Gender: & 2 \\
\hline Male & 6 \\
\hline Female & \\
\hline
\end{tabular}

\section{Results and Discussion}

Results obtained from executing the methodology presented in the previous section is described and discussed below.

\subsection{Existing Visualisation Design Factors}

The selected eleven papers were reviewed individually, and the summaries are presented in Table 2. These factors are presented chronologically. The table presents the author of the paper, the objectives and the visualisation design factors that were extracted from each study.

In the year 2003, Hibbard \& Peters released an initial framework for evaluating and choosing comparative information presentation approaches. They offered eight presentation strategies from three process goals for presenting information. These results were derived from studies of human judgement and decision-making and discussed its implications in supporting informed consumer choices. The strategies presented were relevant to the objective of this study. For instance, the Tailoring strategy is a process of providing customisation of information based on the unique characteristics of the users. By using this strategy, the cognitive burden can be reduced, where less information processing is needed during the decision-making process.

Johnson, Johnson \& Zhang (2004) reported a review of various methods that are involved in the process and present in the life cycle of their redesigning approach. Adding to that, they also presented a case study success on when the methods from this framework were applied. They examined user interfaces with three methods that were related to the aim of this study. For example, the Heuristic Evaluation method is a commonly used technique due to its low cost and low skills requirements. The evaluation can expose the majority of the usability problems within the interfaces, but the local issues with the application cannot be uncovered.

Lipkus (2007) released the best ways in delivering amount of health risks using numeric, verbal and visual formats. These opinions were based on the existing empirical evidence, review papers and books, and consultations on risk communication. Besides that, the formats to use concerning unique risk communication challenges were also discussed. Out of the three types of risks mentioned, the risk in visual communication was the relevant one for this study. A different perspective was mentioned, that was about graphs, where certain type of graphs is well suited for certain tasks. For instance, a pie chart is the best choice when judging proportions, although the pie chart can be biased at times.

Brown, Yen, Rojas \& Schnall (2013) reported the assessment of the appropriateness of the Health IT Usability Evaluation Model (Health-ITUEM) for evaluating the usability of mHealth (mobilehealth) technology. After a few different investigations, nine con- 
cepts of the Health-ITUEM were identified. Although all the concepts introduced were related to usability, a few of it can be related with the designing aspect of a health application. For example, the Learnability concept is relevant because the application usage depends on the users whether or not they can learn quickly how to operate the system. Adding to that, the Flexibility/Customizability concept is also relatable. The system should provide more than one way to complete tasks that allows the users to operate the system as per their preference.

In the year 2014, Parsons \& Sedig released ten essential properties of interactive visual representations. The values of these properties are examined by evaluating the effect of cognitive processing and visual reasoning and show the necessity of making their values adjustable. The properties presented were mostly relevant to the objective of this study. For example, Fidelity is valued by the degree of the information items are accurately presented. Furthermore, the Appearance is also valued by the astatic features by which information items are encoded for an interactive visual.

HealthCare Foundation, California (2014) reported a guide to choose the best visualisation options for the data that is to be resented and explained on how to get started on the path to better data presentation. The guide was achieved by having a case study as a preliminary study. The toolkits presented about 16 factors to look into when visually presenting a set of data. All the factors were related to the aim of this study. For example, the Dashboard helps to summarize the key data points on one page. This gives users a clean area with a limited data point to avoid confusion and force focus. Adding to that, Infographics also have a right amount of impact as a design factor as it can tell compelling stories with data using unique design elements. This can be in different forms, depending on the focus of the application.

Bantug et al. (2016) reported on the key principles of graphical data display relevant to patient-reported outcomes (PRO) data communication. These principles were obtained from the integrated literature review that produced four significant themes. Even though the study was on PRO, the themes can be adapted to our study. Some factors are related to the objective of this study, whereas some were repeated. For instance, the choice of graph format theme and the consider multiple formats theme are corelated. Both the themes separately give an uncertainty on the actual way the graphs should be presented. If the themes were connected, it would provide a clearer picture on how the graphs should be displayed. Besides that, the reduce cognitive burden theme is straightforward, where in a way it can minimise the amount of details that are being conveyed in any graph and reduces the working memory demands.
In recent times, Ola \& Sedig (2016) demonstrated the ways of a framework-based approach could help designers create novel, elaborate, non-trivial visualisations for big health data. They presented four visualisations that are components of a significant tool to understand the large-scale of public health data. Each visualisation was studied from different perspectives that cover different sub-visualisations. For example, the Demography visualisation consists of five sub-visualisations that represent age groups, cause clusters, risk clusters, country (or location) clusters, and relationships or mortality across these facets. The Chronology visualisation on the other hand concerns with the engagements of actions in order of their temporal occurrence.

Recently, Moura, Beer, Patelli \& Lewis (2017) released contemporary views and biases related to human errors in major accidents Moreover, the application on an artificial neural network approach was also shown on some major accident datasets in disclosing common patterns and significant features. They introduced four functions, but only two were related to visualisation, which is temporary and permanent interface functions. Both the functions together had five factors. For instance, Access Limitation factor can restrict a user's movement within the application making them not to use the application anymore.

Sedig et al. (n.d.) presented two levels of interactivity, which are the macro and micro level. The macro level interactivity is used at the operation level from the combination, sequencing and aggregating the properties and relationships of interactions when a user performs an activity. The elements listed can give some idea and help to design and evaluate the interactivity in human-centred visualisation tools. Among the elements presented, the Granularity element was relevant to this study. This element is focused with the essential steps of an action, where the detailing of an action is given importance. Moreover, the Focus element is applicable, the reason being the focal point of an action is to be prioritised when designing interactive health applications.

Yen, Sousa \& Bakken (n.d.) presented a study on web-based communication system which supports nurse staffing and scheduling. The study was done based on a cross-sectional study using Health-ITUES to evaluate users' perception towards the webbased communication system after implementing it. The usability models had four main factors. Even though these factors were a usability-based factor, but some of it is relevant with the aim of this study. For instance, the Perceived ease of use factor focused on the simplicity of the application where users can use it easily. The Error prevention factor also reflected that to send a correct message of the system to the users; the system should avoid having errors that it will give users the trust in using the system full heartedly.

Table 2: A Summary of Visualization Design factors found in related work.

\begin{tabular}{|c|c|c|c|}
\hline No. & Author & Objectives & Design factors \\
\hline 1. & $\begin{array}{l}\text { Hibbard \& } \\
\text { Peters (2003) }\end{array}$ & $\begin{array}{l}\text { The challenge is not merely } \\
\text { to communicate accurate in- } \\
\text { formation to consumers, but } \\
\text { to understand how to present } \\
\text { and target that information } \\
\text { so that it is actually used in } \\
\text { decision-making. }\end{array}$ & $\begin{array}{l}\text { - Decision support tools } \\
\text { - Information intermediary } \\
\text { - Evaluability } \\
\text { - Narratives } \\
\text { - Vividness } \\
\text { - Tailoring } \\
\text { - Framing }\end{array}$ \\
\hline 2. & $\begin{array}{l}\text { Johnson, } \\
\text { Johnson \& } \\
\text { Zhang (2004) }\end{array}$ & $\begin{array}{l}\text { To identify problems within } \\
\text { the original system and un- } \\
\text { cover potential flaws within } \\
\text { the redesigned system. }\end{array}$ & $\begin{array}{l}\text { - Heuristic evaluation } \\
\text { - Key stroke level } \\
\text { - Cognitive walkthrough }\end{array}$ \\
\hline 3. & Lipkus (2007) & $\begin{array}{l}\text { Offers when possible, best } \\
\text { practices for conveying the } \\
\text { magnitude of health risks } \\
\text { using numeric, verbal, and } \\
\text { visual formats. }\end{array}$ & $\begin{array}{l}\text { - Certain type of graphs are well suited for specific tasks } \\
\text { - Judgments of magnitude - graphic displays should be proportional to the quantities depicted } \\
\text { - Individuals are sensitized to graphs that use height to signify risk likelihood or to make risk com- } \\
\text { parisons among events, such as bar graphs and risk ladders. } \\
\text { - Icons, such as human figures, are a common method of displaying the number of individuals af- } \\
\text { fected within a population. }\end{array}$ \\
\hline 4. & $\begin{array}{l}\text { Brown, Yen, } \\
\text { Rojas \& } \\
\text { Schnall } \\
(2013)\end{array}$ & $\begin{array}{l}\text { To assess the appropriate- } \\
\text { ness of the Health IT Usabil- } \\
\text { ity Evaluation Model } \\
\text { (Health-ITUEM) for evaluat- }\end{array}$ & $\begin{array}{l}\text { - Error prevention } \\
\text { - Completeness } \\
\text { - Memorability } \\
\text { - Information needs }\end{array}$ \\
\hline
\end{tabular}




\begin{tabular}{|c|c|c|c|c|}
\hline & & $\begin{array}{l}\text { ing the usability of mHealth } \\
\text { technology }\end{array}$ & \multicolumn{2}{|l|}{$\begin{array}{l}\text { - Flexibility / customizability } \\
\text { - Learnability } \\
\text { - Performance speed } \\
\text { - Competency }\end{array}$} \\
\hline 5. & $\begin{array}{l}\text { Parsons \& } \\
\text { Sedig (2014) }\end{array}$ & $\begin{array}{l}\text { Examines how the values of } \\
\text { these properties affect cogni- } \\
\text { tive processing and visual } \\
\text { reasoning and demonstrate } \\
\text { the necessity of making their } \\
\text { values adjustable-all of } \\
\text { which is situated within a } \\
\text { broader theoretical } \\
\text { framework concerned with } \\
\text { human-information interac- } \\
\text { tion in complex cognitive } \\
\text { activities. }\end{array}$ & \multicolumn{2}{|l|}{$\begin{array}{l}\text { - Appearance } \\
\text { - Complexity } \\
\text { - Configuration } \\
\text { - Density } \\
\text { - Dynamism } \\
\text { - Fidelity } \\
\text { - Fragmentation } \\
\text { - Interiority } \\
\text { - Scope } \\
\text { - Type }\end{array}$} \\
\hline 6. & $\begin{array}{l}\text { HealthCare } \\
\text { Foundation, } \\
\text { California } \\
(2014)\end{array}$ & $\begin{array}{l}\text { A guide to select the best } \\
\text { visualisation options for your } \\
\text { data and explains how to get } \\
\text { started on the path to better } \\
\text { data presentation. }\end{array}$ & \multicolumn{2}{|c|}{$\begin{array}{l}\text { - Speak with numbers } \\
\text { - Tables and rankings } \\
\text { - Graphs, charts and maps (bar, line, pie, stacked bar, tree, chloropleth, cartograms, pinpoint, pro- } \\
\text { portional symbols) } \\
\text { - Dashboards } \\
\text { - Infographics } \\
\text { - Animated visualisations } \\
\text { - Static visualisations } \\
\text { - Interactive visualisations }\end{array}$} \\
\hline 7. & $\begin{array}{l}\text { Bantug et al. } \\
(2016)\end{array}$ & $\begin{array}{l}\text { To address the effectiveness } \\
\text { of graphic display of PRO } \\
\text { data in clinical practice by } \\
\text { reviewing existing literature, } \\
\text { and current recommenda- } \\
\text { tions, regarding graphic } \\
\text { presentations of PROs }\end{array}$ & \multicolumn{2}{|c|}{$\begin{array}{l}\text { - Choose format according to the communication goal } \\
\text { - Minimize the amount of detail conveyed in any one graph } \\
\text { - Reduce working memory demands } \\
\text { - Cleveland and Mcgill hierarchy of most precisely interpreted formats } \\
\text { - Consider using different formats to communicate complex data (but beware of cognitive burden) }\end{array}$} \\
\hline 8. & $\begin{array}{l}\text { Ola \& Sedig } \\
(2016)\end{array}$ & $\begin{array}{l}\text { Demonstrate how a frame- } \\
\text { work-based approach can } \\
\text { help designers create novel, } \\
\text { elaborate, non-trivial } \\
\text { visualizations for big health } \\
\text { data. }\end{array}$ & \multicolumn{2}{|l|}{$\begin{array}{l}\text { - Demography visualization } \\
\text { - Chronology visualization } \\
\text { - Geography visualization } \\
\text { - Overview visualization }\end{array}$} \\
\hline 9. & $\begin{array}{l}\text { Moura, Beer, } \\
\text { Patelli \& } \\
\text { Lewis (2017) }\end{array}$ & $\begin{array}{l}\text { To convert high-dimensional } \\
\text { accident data into a conven- } \\
\text { ient graphical alternative, to } \\
\text { overcome barriers to com- } \\
\text { municate risk and enable } \\
\text { stakeholders to fully } \\
\text { understand and learn from } \\
\text { major accidents. }\end{array}$ & \multicolumn{2}{|l|}{$\begin{array}{l}\text { - Access limitations } \\
\text { - Ambiguous information } \\
\text { - Incomplete information } \\
\text { - Access problems } \\
\text { - Mislabeling }\end{array}$} \\
\hline 10 & $\begin{array}{l}\text { Sedig et al. } \\
\text { (n.d.) }\end{array}$ & $\begin{array}{l}\text { Provide some structure and } \\
\text { facilitate a systematic ap- } \\
\text { proach to design and evalua- } \\
\text { tion of interactivity in } \\
\text { human-centred visualisation } \\
\text { tools. }\end{array}$ & 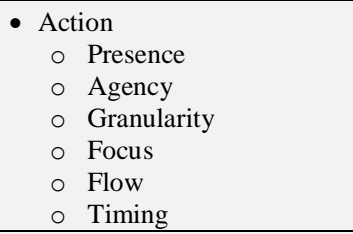 & $\begin{array}{l}\text { - Reaction } \\
\circ \text { Activation } \\
\circ \text { Flow } \\
\circ \text { Transition } \\
\circ \text { Spread } \\
\circ \text { State } \\
\circ \text { Context } \\
\end{array}$ \\
\hline 11 & $\begin{array}{l}\text { Yen, Sousa \& } \\
\text { Bakken (n.d.) }\end{array}$ & $\begin{array}{l}\text { We advanced the develop- } \\
\text { ment of Health-ITUES to } \\
\text { examine its construct valid- } \\
\text { ity and predictive validity. }\end{array}$ & \multicolumn{2}{|l|}{$\begin{array}{l}\text { - Quality of work life } \\
\text { - Perceived usefulness } \\
\text { - Perceived ease of use } \\
\text { - User control }\end{array}$} \\
\hline
\end{tabular}

It is apparent from Table 2, the reviewed papers suggested a different set of design factors that can be considered in developing self-care visuals in health support applications. The design factors reviewed are of different depths and dimensions. Some of the design factors were too specific, while the others were found to be too general. For instance, "mislabelling" (suggested by Moura et al. (2017)) is a specific design factor that emphasises its importance to overcome the barrier to communicate risk through visualisations. Parsons \& Sedig (2014) suggested the inclusion of "scope" as one of its design factors, which may appear to be very general and rather obvious to developers.

Although a few selected papers were not related to the aim of this study, the design factors that they mentioned were somehow relatable with visualisations. For example, Johnson, Johnson and Zhang (2004) stated the factors that should be looked into when redesigning a system like the keystroke level. As this is a usability factor, it should be considered when designing healthcare applications where elderly users would feel helpful when they use the application with minimal keystroke level. Besides that, recently, Sarikaya, Gleicher and Szafir (2018) published the design factors that were included in summary visualisation in visual analytics. Although those factors were somehow focused on the visuals presented in visual analytics, the data summarisation method can be considered when designing the dashboard feature in healthcare applications where users are able to see the summary of their data easily.

On the whole, each paper follows a different objective and can be very useful to develop a specific application in the healthcare industry. Many unique design factors are suggested, although some of them are found to be commonly mentioned. However, none of the papers solely meet the intent of this study, which is to develop a holistic set of design factors to aid the development of self- 
reflective visualisations in health support applications. Hence, a combination of design factors is necessary to design ideal self-care visuals in health support applications. Apart from extracting design factors from existing studies, we have conducted a FGD with a group of users in determining their perspective and requirements towards self-care visuals presented below.

\subsection{User Perception of Self-Care Visuals}

The information derived from the focus group study session were divided into eight themes - Motivation \& Commitment, Customizability, Personalisation, Accessibility, Complex yet Comprehensible Graphs, Alerts \& Proactive Support and Trust \& Privacy.

\subsubsection{Motivation and Commitment}

There are a few factors that can motivate the participants and keep them committed to changing their lifestyle with a health application. Among the most crucial factor would be the designs and the features within the application. One of the participants expressed: "If the application gives me information that I did not know before this regarding my health condition with accurate calculations and reading, I would be committed in using the application often". They said that the interest in having some changes must come from within themselves. Self-discipline is believed to a be an important factor when using these self-care applications. Adding to that, all of them felt that, when they see their health changes clearly such as the decrease in their bodyweight after exercising, they feel excited to exercise more to see more changes in their body weight and their appearance as well.

\subsubsection{Customizability}

The participants had a few different opinions on the display of colours and the font sizes within the application. Some of them wanted vibrant colours and some wanted subtle colours. The font sizes also varied according to the age group, where participants below 40 years of age felt that the fonts did not matter, but then the older aged participants preferred big and bold fonts. Both of these factors can change the usability of an application. Therefore, as all of them agreed, the application should be customizable according to the age group of the users who engage with the application.

\subsubsection{Personalisation}

Participants felt that they loved to personalise the application to encourage them to use the application more often. One of them expressed: "I should be able to choose what I want to see on a daily basis, even though the application has many features". Another firmly said, "I prefer not to see other features that I do not use every day while using the application". The application versatility changes the whole thoughts and opinions of the users when using the application to check on their health conditions.

\subsubsection{Accessibility}

It is apparent that features displayed in an application plays a vital role in captivating the users to use it often. Menus and toolbars are key features that help users to navigate around the application. A few of the participants expressed some of their experiences from using applications with bad menus and toolbar features. They faced a lot of difficulties in navigating from one page to another, not knowing where to click and scroll through the application.

Besides that, icons can change perceptions of users on the function of the feature. It can mislead users on the function of feature that they are looking for through the application. One said, "Sometimes the icons are displayed for the sake of displaying something. But generally, the icons displayed are kept simple with straightforward meanings for users of any age to understand easily". Fa- miliar icons should be used to give users a chance to adapt to the application easily.

The screen and device compatibility of an application accommodates all types of mobile platforms and operating systems when using the application. Some mentioned that they preferred to have applications that are versatile in both web-based as websites and mobile-based as apps for their convenience. This would make them engage with the application more and be interested in checking on their health often.

\subsubsection{Complex Yet Comprehensible Graphs}

When graphs are concerned, the participants had different thoughts and took on it. Majority of the participants felt comfortable in seeing their health results in the form of graphs, but a few of them preferred numbers such as percentages or consolidated report form than reports solely with graphs. They said that graphs often panic and scares them because of the complexity of it.

Graphs should be kept simple and with the suitable amount of details at the same time. One of them said, "I feel that graphs are important in reflecting my health progresses, but it should be clear and not too complex". She also said that graphs make her to understand her health and body better. Another participant added that the graphs presented should be suitable with the input obtained from the users. Users can be misled psychologically if the graph goes low or high all of a sudden without proper details explaining the drastic change in their readings. One of them mentioned that, "Graphs displayed should be easily understandable for users who are not health literate. The units given should also be explained briefly”.

\subsubsection{Alerts and Proactive Support}

Generally, alerts given from health applications are often considered as a preferred feature. However, there are cases where such alerts may result otherwise. For instance, receiving alerts too frequently from the application may annoy users (e.g. reminders to track their food intake for every meal they eat), which in result may cause the user to ignore all the alerts or even quit using the application. One of the participants voiced: "I prefer to receive alerts from the application if my health progress is alarming and in a dangerous state." Another participant felt that the alerts should probably be given by stages, where the users can be aware of the changes in their health trends sooner before it's gone too far. She also said that the alerts should be backed-up with some recommendations for the users to try temporarily to change their health readings. This can avoid users' from getting anxiety attacks on thinking of the ways to overcome their alarming health changes. These recommendations make users to be more active and give them the boost to change their health condition for their betterment. The older participants feel supported in monitoring their health if they had their spouse or their clinician connected with them through the application. The clinicians could give them some advice on the do's and don'ts when following a certain dieting routine. One of the participants expressed: "Although it is nice to be connected to support my spouse or a close family through the application, but sometimes when the readings and reports show the bad progress I feel that I might get stressed and get emotionally drained out by thinking about it".

\subsubsection{Trust and Privacy}

The participants have common thought when it comes to trusting the application. They are always sceptical whether the facts that they get from the application are all true. The benefit of the doubt should be given to the application users, but they should always survey an application before using it. One of them said: "I usually compare my health readings that I receive from the app with the reading that I take manually when I check my weight”. By doing 
this, she said that it gives her the confidence to trust the application of the readings match.

Health issues is a sensitive topic that many do not prefer to talk about neither within their close family members nor with their spouse. A participant expressed that: "I do not like sharing my health or medical issues with anybody, other than my doctor". She added that she feels that these issues are personal to her and her body where she does not like sharing it with her spouse much. Even though some were reluctant in sharing their health matter with anyone, some on the other hand choose to share their medical or health matters with their close family members or spouse, sometimes both. They said that they want their family to know their medical history in case of a medical emergency.

\section{A conceptual Model to Design Self- Reflective Visualisations}

Based on the review of existing design factors and user requirements presented in the previous sections, we proposed a conceptual model for healthcare visualisations in novel self-care applications.

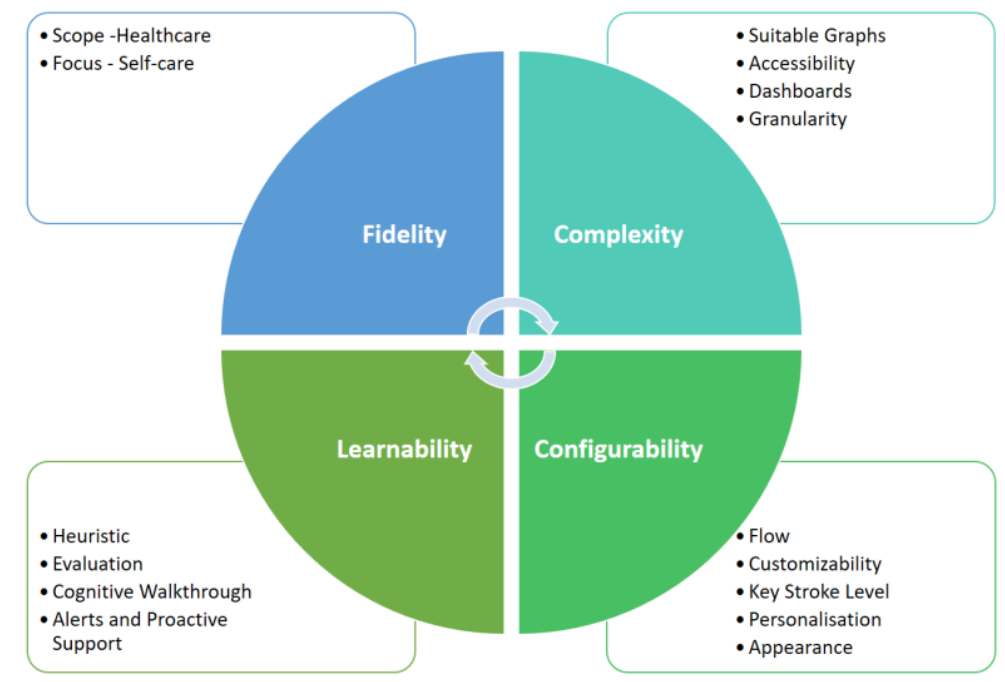

Fig. 3: Dimensions and design principles of self-care visuals.

Illustrated in Figure 3 is a conceptual model that presents a list of design principles that are ideal to be considered when designing self-care applications. The ultimate motive of the model is to produce self-reflective health visuals in self-care applications. The model is divided into four different dimensions: Fidelity, Complexity, Learnability and Configurability. Each dimension branch out to a few design principles.

Fidelity is the degree of exactness of which something is copied or reproduced. Thus, this dimension draws the attention to the main purpose of the application. The two principles, Scope and Focus, can help developers to concentrate on the objective of the application. In terms of scope, it is essential to ensure that the visuals should only present what is relevant to avoid any confusion, a state whereby the users not being able to associate the link between the elements presented in the visual. The focus should be on self-care, where the visuals solely can help users to know about their health trends.

Besides that, Complexity is the state or quality of being intricate or complicated. In this dimension, the intricacy of the elements within the application will be of focus. Therefore, the principles are Suitable Graphs, Accessibility, Dashboards, and Granularity. Suitable Graphs are essential features of the health application where users depend on these graphs to check on their health progress. These graphs should be carefully formatted according to the suitable dataset available to be self-reflective to the users. Misinterpretation of the message can happen if the graphs are not suitable with the type of data that is being presented. Furthermore, Accessibility covers menus \& toolbars, icons and screen $\&$ device compatibility. Menus and toolbars are features that help users to navigate around the application which should be placed carefully at an ideal side of the screen for easy navigation. Icons are the little figuring or symbols that work as shortcut symbols for users to identify one of the features in the application. Screen and device compatibility is essential because this will determine that users who have mobile phones operating on all operating system, where Windows, Apple, or Android are included. Adding to this, the Dashboard is a home page on a website or a system giving access to different elements of the application's functionality. This principle would be able to provide a summary for users to know the features and functionalities that they are dealing within the application. Granularity is the scale or level of detailing of a set of data, where the data presented in the visuals to the users should be detailed yet kept in a simple, understandable manner.

Learnability is another dimension that targets the capability of the users to learn on how to use the application. The goal is to make users to quickly learn the ways to use the application with proper guidance and remember the ways to manoeuvre around the application. Hence, the principles are Heuristic Evaluation, Alerts \& Proactive Support and Cognitive Walkthrough. Heuristic Evaluation is where the users should be able to discover or learn something by themselves without any assistance when using the application, solely depending on the visuals. Alerts and Proactive Support is the feature where the users are prompted with notifications and given recommendations when needed when using the application. Usability of the visuals should be evaluated before deployment. A Cognitive Walkthrough would enable one to gauge the understanding of the system's learnability of the potential users.

The Configurability dimension concentrates on the arrangement of parts or elements within the application from when the user login page till the user logs out. Thus, the principles are Flow, Customizability, Key Stroke Level, Personalization and Appearance. The Flow is the action of moving along in a steady, continuous movement. The visuals should have continuity between it to help users to use the application without confusion. Customizability is the factor where the application should be customised for users according to their age group. The size and colours of the fonts should be customizable for users to have a personal touch when engaging with the application. The Key Stroke Level should be kept at a minimal level to lets users benefit from one page to another properly without needing to go back and forth. This includes keystrokes, pointing, clicking, thinking, waiting, and deciding. Personalization is a favorite feature where users get to change what they want to see on their feed or page on a daily basis and 
gets them connected more to the application. Appearance is the overall impression of the visuals in the application that should be presentable. It should appear as simple and as user-friendly as possible.

\section{Conclusion and Future Works}

The current study reviewed healthcare visualisation design factors from existing studies and a focus group study conducted with a group of mobile application users. Results indicate that existing guidelines for healthcare visuals are mostly focused on a specific type of application, and they predominantly encompass usability aspects of the visual. Furthermore, self-care application users are expecting healthcare visuals that are more accommodating and user-friendly with easily adaptable features that would enable them to better understand their health conditions. Based on the findings, we proposed and presented a conceptual model that consists of a set of design principles for self-reflective visualisations in novel health support applications. This model will need to be validated by experts and self-care application users.

\section{Acknowledgement}

This study is funded by Universiti Tenaga Nasional under the UNITEN Internal Research Grant (UNIIG 2017). We thank the participants for their time and willingness to share their viewpoints with us.

\section{References}

[1] Bantug, E. T., Coles, T., Smith, K. C., Snyder, C. F., Rouette, J., \& Brundage, M. D. (2016). Graphical displays of patient-reported outcomes (PRO) for use in clinical practice: What makes a pro picture worth a thousand words? Patient Education and Counseling, 99, 483-490. https://doi.org/10.1016/j.pec.2015.10.027

[2] Brown Iii, W., Yen, P.-Y., Rojas, M., \& Schnall, R. (2013). Assessment of the Health IT Usability Evaluation Model (HealthITUEM) for evaluating mobile health (mHealth) technology. https://doi.org/10.1016/j.jbi.2013.08.001

[3] HealthCare Foundation, C. (2014). Worth a Thousand Words: How to Display Health Data. Retrieved from http://www.chcf.org/ /media/MEDIA LIBRARY Files/PDF/PDF W/PDF WorthThousandWordsDataViz.pdf

[4] Hibbard, J. H., \& Peters, E. (2003). SUPPORTING INFORMED CONSUMER HEALTH CARE DECISIONS: Data Presentation Approaches that Facilitate the Use of Information in Choice. Annu. Rev. Public Health, 24, 413-33. https://doi.org/10.1146/annurev.publhealth.24.100901.141005

[5] Johnson, C. M., Johnson, T. R., \& Zhang, J. (2004). A usercentered framework for redesigning health care interfaces. https://doi.org/10.1016/j.jbi.2004.11.005

[6] Johnson, C. M., \& Shaw, R. J. (2012). A usability problem: conveying health risks to consumers on the Internet. AMIA ... Annual Symposium Proceedings. AMIA Symposium, 2012, 427-35. Retrieved from http://www.ncbi.nlm.nih.gov/pubmed/23304313

[7] Laubheimer, P. (2017). Dashboards: Making Charts and Graphs Easier to Understand. Retrieved March 30, 2018, from https://www.nngroup.com/articles/dashboards-preattentive/

[8] Lee, S.-Y. D., Arozullah, A. M., \& Cho, Y. I. (2004). Health literacy, social support, and health: a research agenda. Social Science \& Medicine, 58(7), 1309-1321. https://doi.org/10.1016/S02779536(03)00329-0

[9] Lipkus, I. M. (n.d.). Numeric, Verbal, and Visual Formats of Conveying Health Risks: Suggested Best Practices and Future Recommendations. https://doi.org/10.1177/0272989X07307271

[10] Moura, R., Beer, M., Patelli, E., \& Lewis, J. (2017). Learning from major accidents: Graphical representation and analysis of multiattribute events to enhance risk communication. Safety Science, 99 58-70. https://doi.org/10.1016/j.ssci.2017.03.005

[11] Ola, O., \& Sedig, K. (2016). Beyond simple charts: Design of visualizations for big health data. Online Journal of Public Health Informatics, 8(3), e195. https://doi.org/10.5210/ojphi.v8i3.7100
[12] Parsons, P., \& Sedig, K. (2014). Adjustable properties of visual representations: Improving the quality of human-information interaction. Journal of the Association for Information Science and Technology, 65(3), 455-482. https://doi.org/10.1002/asi.23002

[13] Sedig, K., Parsons, P., Dittmer, M., Haworth, R., Parsons, P., Haworth Student, B. R., ... Huang, W. (n.d.). Human-Centered Interactivity of Visualization Tools: Micro-and Macro-level Considerations. https://doi.org/10.1007/978-1-4614-7485-2

[14] Sultan, S., \& Mohan, P. (2012). Designing a Peer-Facilitated SelfManagement Mobile Application: A User-Centred Approach. In Proceedings of the 6th International Conference on Pervasive Computing Technologies for Healthcare. IEEE. https://doi.org/10.4108/icst.pervasivehealth.2012.248707

[15] Yen, P.-Y., Sousa, K. H., \& Bakken, S. (n.d.). Examining construct and predictive validity of the Health-IT Usability Evaluation Scale: confirmatory factor analysis and structural equation modeling results. https://doi.org/10.1136/amiajnl-2013-001811

[16] PatientsLikeMe | Conditions. (n.d.). Retrieved March 21, 2018, from https://www.patientslikeme.com/conditions

[17] Sarikaya, A., Gleicher, M., \& Szafir, D. A. (2018). Design Factors for Summary Visualization in Visual Analytics (Vol. 37). Retrieved from http://danielleszafir.com/pubs/summaries-preprint.pdf 